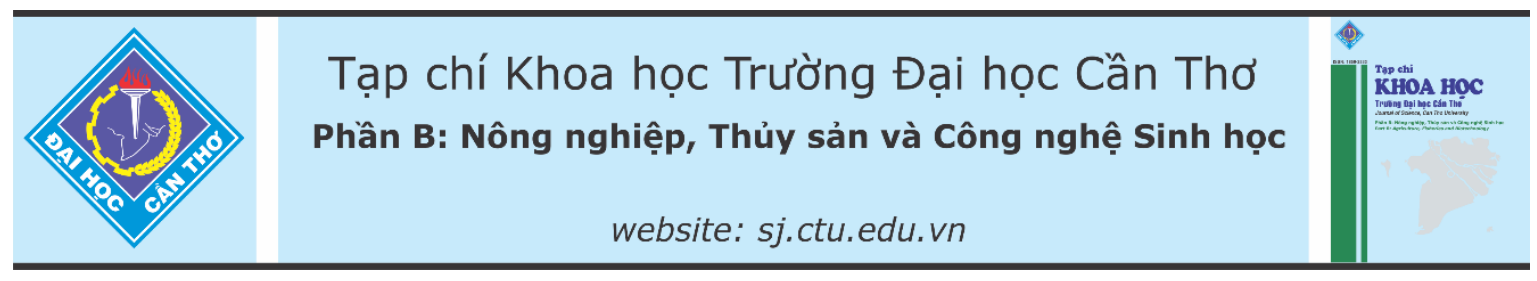

DOI: $10.22144 /$ ctu.jvn.2021.126

\title{
KHẢ NĂNG CHUYỂN HÓA ĐẠM CỦA CHỦNG VI KHUẨN NITRATE HÓA CHỌN LỌC SỬ DỤNG CHO Hệ THỐNG LỌC TUẦN HOÀN TRONG NUÔI TRỒNG THỦY SẢN
}

Phạm Thị Tuyết Ngân*, Vũ Hùng Hải, Vũ Ngọc Út và Huỳnh Trường Giang

Bộ môn Thủy sinh học ứng dụng, Khoa Thủy sản, Truờng Đại học Cần Tho

*Người chịu trách nhiệm về bài viết: Phạm ThịTuyết Ngân (email: pttngan@ctu.edu.vn)

\section{Thông tin chung:}

Ngày nhận bài: 22/02/2021

Ngày nhận bài sủa: 24/04/2021

Ngày duyệt đăng: 20/08/2021

\section{Title:}

Evaluation of the nitrification efficacy of selected nitrifying bacteria in recirculating aquaculture systems

\section{Tù̀ khóa:}

$A O B, N O B$, tôm the chân trắng, vi khuẩn nitrate hóa

\section{Keywords:}

$A O B$, Nitrifying bacteria, $N O B$, white leg shrimp

\begin{abstract}
This study was carried out to evaluate the nitrogen conversion of selected nitrifying bacteria from shrimp ponds used for the recirculating system in shrimp culture tanks. The experiment consisted of 4 treatments: Control: no addition of bacteria; Treatment 1: added bacteria AOB TB7.2; Treatment 2: added NOB TV4.2 and Treatment 3: added a mixture of bacteria $A O B T B 7.2$ and NOB TV4.2; each treatment was repeated 3 times. The results showed that the addition of bacteria $A O B$ TB7.2 and $N O B$ TV4.2 to the biofilter of circulatory system reduced the concentration of toxic gases such as ammonia and nitrite in the culture tank, and significantly increased shrimp survival. Moreover, there was no discharged water throughout the culture cycle could minimize the impact on the outside environment. Adding a combination of AOB TB7.2 and $N O B$ TV4.2, the nitrification process took place faster than single supplementation. Nitrification and nitrification rate increased with bacteria addition treatments compared to the control (7 and 14 versus 14 and 35 days, respectively).
\end{abstract}

\section{TÓM TẮT}

Đề tài được thực hiện nhằm đánh giá khả năng chuyển hóa đạm của các chủng vi khuẩn nitrate hóa chọn lọc tù ao nuôi tôm sủ dụng cho hệ thống lọc tuần hoàn trong nuôi tôm thẻ trên bể. Thi nghiệm gồm 4 nghiệm thức, mối nghiệm thức lập lại 3 lần. Đối chúng: không bổ sung vi khuẩn; 2) Nghiệm thức 1: bổ sung vi khuẩn $A O B$ TB7.2; Nghiệm thức 2: bổ sung vi khuẩn NOB TV4.2 và Nghiệm thức 3: bổ sung hồn hợp vi khuẩn $A O B$ TB7.2 và NOB TV4.2. Kềt quả cho thấy việc bổ sung vi khuẩn $A O B$ TB7.2 và vi khuẩn NOB TV4.2 vào bể lọc sinh học trong hệ thống tuần hoàn làm giảm hàm lượng các khí độc ammonia và nitrite trong bể nuôi, tăng tỉ lẹ sống, khác biệt có ý nghĩa thống kê đồng thời tái sư dụng được nguồn nước trong suốt chu kỳ nuôi, giảm thiểu tác động đến môi truờng bên ngoài. Bổ sung kết hợp $A O B$ TB7.2 và NOB TV4.2 quá trình nitrate hóa diễn ra nhanh hơn so với bổ sung đon dòng. Quá trình nitrite hóa và nitrate hóa diễn ra sớm hơn ở các nghiệm thức có bổ sung vi khuẩn so với đối chúng (nitrite hóa và nitrate hóa là 7 ngày và 14 ngày; 14 ngày và 35 ngày lần luọt ở nghiệm thức bổ sung vi khuẩn và đối chứng). 


\section{GIỚI THIỆ}

Trong nuôi trồng thủy sản, nhóm vi khuẩn nitrate hóa được sử dụng rất phổ biến để xử lý nước trong lĩnh vực sản xuất giống thủy sản và nuôi thâm canh. Quy trình sản xuất được thực hiện thông qua hệ thống lọc sinh học tuần hoàn. Ở các bể lọc sinh học, vi khuẩn oxy hóa amonia (Nitrosomonas) sẽ chuyển hóa $\mathrm{NH}_{3}$ thành $\mathrm{NO}_{2}$, kế đến vi khuẩn oxy hoá nitrite (Nitrobacter) chuyển hóa $\mathrm{NO}_{2}^{-}$thành $\mathrm{NO}_{3}{ }^{-}$. Nước sau khi xử lý qua bể lọc sinh học hoàn toàn không độc cho tôm cá và được tái sử dụng để ương nuôi. Suốt quá trình nuôi, nước sẽ tuần hoàn trong một hệ thống kín và hoàn toàn không thay nước, chỉ có một lượng nhỏ nước mới được cấp thêm vào hệ thống để bù đắp cho lượng nước hao hụt do bốc hơi. Các vi khuẩn tham gia vào quá trình nitrate hóa là vi khuẩn hóa vô cơ tự dưỡng, các loài vi khuẩn nitrate hóa thường gặp là Nitrosomonas europaea, Nitrobacter vinogradskii, Nitrobacte ragilis, Nitrospina gracilis, Nitrococcus mobilis (Stephen et al., 1996). Hiện nay, các nước phát triển đã ứng dụng rất thành công quy trình lọc sinh học tuần hoàn trong sản xuất thâm canh cá trê phi, cá chình, cá hồi, cá bơn và cả cá rô phi (Carroll et al., 2005; William et al., 2009; Mordenti et al., 2014; Luo et al., 2014; Palm et al., 2018). Quy trình sản xuất có thể dựa hoàn toàn vào nhóm vi sinh vật chuyển hóa đạm tự nhiên (vi khuẩn nội sinh), tuy nhiên để quá trình nitrate hóa diễn ra nhanh chóng và hiệu quả, việc chủ động bổ sung nhóm vi khuẩn này vào hệ thống lọc tuần hoàn sẽ giảm thời gian khởi động của bể lọc tuần hoàn từ 3 tuần xuống 1 tuần (Gromen et al., 2002). Ở nước ta, chế phẩm sinh học được sử dụng rất phổ biến chủ yếu là vi khuẩn nhóm phân huỷ các chất hữu cơ (Bacillus), trong khi đó chế phẩm vi sinh có thành phần là vi khuẩn nitrate hóa còn rất hạn chế (Vũ Thế Trụ, 2012). Vì vậy việc nghiên cứu khảo sát khả năng chuyển hóa đạm của chủng vi khuẩn nitrate hóa chọn lọc từ ao nuôi tôm sử dụng cho hệ thống lọc tuần hoàn là rất cần thiết nhằm tuyển chọn các chủng vi khuẩn chuyển hoá đạm hiệu quả làm chế phẩm vi sinh phục vụ nuôi trồng thủy sản.

\section{PHƯƠNG PHÁP NGHIÊN CÚU}

\section{1. Đối tượng thí nghiệm}

Các chủng vi khuẩn oxy hóa ammonia ( $\mathrm{AOB})$ TB7.2 và oxy hóa nitrite (NOB) TV4.2 được chọn để bố trí thí nghiệm có nguồn gốc phân lập từ mẫu bùn ao nuôi tôm và bảo quản tại phòng thí nghiệm Vi sinh vật hữu ích, Bộ môn Thủy sinh học ứng dụng, Khoa Thủy sản, Trường Đại học Cần Thơ.
Tôm thẻ chân trắng (Litopenaeusvannamei) được chọn từ khu Trại thực nghiệm, bộ môn Thủy sinh học ứng dụng, Khoa Thủy sản, Trường Đại học Cần Thơ. Tôm được thuần hóa với độ mặn $15 \%$ trong bể $5 \mathrm{~m}^{3}$ ở nhiệt độ $28-29^{\circ} \mathrm{C}$ khoảng 2 tuần trước khi bố trí thí nghiệm. Trong thời gian thuần hóa, tôm được cho ăn 2 lần mỗi ngày bằng thức ăn viên công nghiệp Nasa 2202 (40\% hàm lượng đạm thô, $6 \%$ lipid thô và $4 \%$ tro; CP Group Co., Ltd., Việt Nam) với tỉ lệ $5 \%$ trọng lượng thân.

\subsection{Phương pháp chuẩn bị vi khuẩn}

Vi khuẩn $\mathrm{AOB}$ TB7.2 và NOB TV4.2 được phục hồi và nuôi tăng sinh lần lượt trong môi trường khoáng cơ bản (gồm $0,1 \mathrm{~g} \mathrm{MgSO} 4.7 \mathrm{H}_{2} \mathrm{O} ; 13,5 \mathrm{~g}$ $\mathrm{Na}_{2} \mathrm{HPO}_{4} ; 0,7$ g KH $\mathrm{KO}_{4} ; 0,01$ g $\mathrm{FeCl}_{3} ; 0,18 \mathrm{~g}$ $\mathrm{CaCl}_{2} .2 \mathrm{H}_{2} \mathrm{O} ; 0,5 \mathrm{~g} \mathrm{NaHCO}_{3} ; 15 \mathrm{~g} \mathrm{NaCl}$ và $1000 \mathrm{~mL}$ nước cất) bồ sung $0,5 \mathrm{~g} / \mathrm{L}\left(\mathrm{NH}_{4}\right)_{2} \mathrm{SO}_{4}$ đối với vi khuẩn $\mathrm{AOB}$ và $0,5 \mathrm{~g} / \mathrm{L} \mathrm{NaNO}_{2}$ với vi khuẩn $\mathrm{NOB}$ (Spieck \& Bock, 2005). Vi khuẩn được nuôi trên máy lắc với tốc độ 200 vòng/phút trong điều kiện che tối ở $28^{\circ} \mathrm{C}$. Sau 7 ngày nuôi, sinh khối tế bào được thu và pha loãng với nước muối sinh lý sau khi ly tâm ở tốc độ 3.500 vòng/phút trong 10 phút ở $4^{\circ} \mathrm{C}$, sau đó điều chỉnh dung dịch huyền phù vi khuẩn với môi trường tương ứng để đạt giá trị mật độ quang OD $0.25 \pm 0.05$ ở bước sóng $600 \mathrm{~nm}$ (tương ứng với mật độ vi khuẩn $10^{6} \mathrm{CFU} / \mathrm{mL}$ ) và kiểm tra lại bằng phương pháp trải đĩa thạch trên môi trường khoáng cơ bản tương ứng cho vi khuẩn $\mathrm{AOB}$ và $\mathrm{NOB}$ (Karthik et al., 2015).

\subsection{Bố trí thí nghiệm}

Thí nghiệm được bố trí trên hệ thống tuần hoàn gồm 3 bể nuôi $500 \mathrm{~L}$, bể lắng cơ học $500 \mathrm{~L}$ và bể lọc sinh học 500 L. Trong đó, bể lọc sinh học được thiết kế theo Ray and Lotz (2017) chứa $20 \%$ thể tích giá thể di động (moving bed bioreactor [MBBR], Mã hiệu PE50; kích cỡ: $\Phi 25 \times 4$; diện tích bề mặt: 600 $\mathrm{m}^{2} / \mathrm{m}^{3}$ ). Các bể nuôi và bể giá thể được duy trì sục khí liên tục và chứa $80 \%$ thể tích nước ở độ mặn $15 \%$. Tôm có trọng lượng trung bình $0,47 \pm 0,1 \mathrm{~g}$ bố trí vào bể với mật độ 100 cá thể/bể. Mỗi bể được che $3 / 4$ diện tích bề mặt bằng lưới đen để duy trì độ trong của nước từ $30-40 \mathrm{~cm}$ và tránh tiếp xúc trực tiếp với ánh sáng. Thí nghiệm được thiết kế gồm bốn hệ thống tuần hoàn riêng biệt tương ứng với từng nghiệm thức:

Đối chứng: không bổ sung vi khuẩn.

Nghiệm thức 1: bổ sung vi khuẩn AOB TB7.2

Nghiệm thức 2: bổ sung vi khuẩn NOB TV4.2 
Nghiệm thức 3: bổ sung vi khuẩn AOB TB7.2 và $\mathrm{NOB}$ TV4.2

Mỗi nghiệm thức bố trí lặp lại ba lần và theo dõi trong 63 ngày nuôi. Vi khuẩn được cấy vào bể chứa giá thể sinh học theo từng nghiệm thức (để đạt mật số $10^{5} \mathrm{CFU} / \mathrm{mL}$ ) trước khi bố trí tôm 1 ngày và bổ sung vi khuẩn định kỳ 2 tuần/lần trong suốt quá trình nuôi (Suantika et al., 2017).

\subsection{Chăm sóc và quản lý}

Tôm được cho ăn 3 lần mỗi ngày bằng thức ăn viên công nghiệp Nasa 2202 (40\% hàm lượng đạm thô, $6 \%$ lipid thô và $4 \%$ tro; $\mathrm{CP}$ Group Co., Ltd., Việt Nam) tương ứng với 5-8\% trọng lượng thân và theo dõi lượng thức ăn hàng ngày để điều chỉnh lượng thức ăn cho phù hợp. Hoạt động của tôm thường xuyên được theo dõi. Trong suốt quá trình nuôi, cặn ở đáy bể được siphon định kỳ 3 ngày/lần và cấp thêm lượng nước để bù lại lượng nước siphon ra, hệ thống sục khí trong bể nuôi luôn được điều chỉnh nhằm duy trì hàm lượng oxy hòa tan ở mức > $4 \mathrm{mg} / \mathrm{L}$.

\subsection{Các chỉ tiêu theo dõi}

Môi trường nước: nhiệt độ, $\mathrm{pH}$, độ mặn và hàm lượng oxy hòa tan được đo hàng ngày bằng máy đo đa chỉ tiêu HI9828 (Hanna, Rumani), các chỉ tiêu

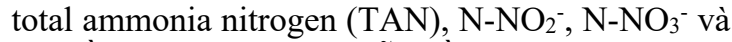
độ kiềm được đánh giá mỗi tuần và phân tích theo phương pháp chuẩn APHA (2017).

Tăng trưởng của tôm: khối lượng của tôm được xác định sau 63 ngày thí nghiệm. Số tôm chết được ghi nhận mỗi ngày. Tỉ lệ sống (SR), tốc độ tăng trưởng tuyệt đối (DWG) và tốc độ tăng trưởng tương đối (SGR) của tôm được đánh giá theo công thức sau:

Tỷ lệ sống của tôm $(\mathrm{SR})(\%)=$ (số tôm thu được/số tôm ban đầu) * 100

Tốc độ tăng trưởng tuyệt đối (DWG, g/ngày) = (W1-W2)/T
Tốc độ tăng trưởng tương đối (SRG, \%/ngày) = $100 *(\ln \mathrm{W} 2-\ln \mathrm{W} 1) / \mathrm{T}$

(Trong đó: $\mathrm{W} 1$ : khối lượng tôm ban đầu $(\mathrm{g})$; $\mathrm{W} 2$ : khối lượng tôm lúc thu mẫu (g) và $\mathrm{T}$ : Số ngày nuôi).

\subsection{Xử lý số liệu}

Số liệu thu thập được tính toán và thể hiện bằng giá trị trung bình \pm độ lệch chuẩn. Các dữ liệu tỉ lệ sống và tăng trưởng khối lượng $(\%)$ được chuyển về arcsine trước khi xử lý ANOVA và phân tích so sánh thống kê giữa nghiệm thức đối chứng và bổ sung vi khuẩn ở mức tin cậy $95 \%$ bằng phần mềm SPSS 20.0 .

\section{KẾT QUẢ VÀ THẢO LUẬN}

\subsection{Nhiệt độ và pH}

Trong suốt quá trình thí nghiệm, nhiệt độ ghi nhận ở các bể nằm trong khoảng thích hợp cho tôm nuôi và ít có biến động giữa các nghiệm thức (từ $28,4-29,7^{\circ} \mathrm{C}$ ). Theo báo cáo trước đây của Thái Bá Hồ và ctv. (2003) cho rằng nhiệt độ tốt nhất cho sự sinh trưởng của tôm thẻ chân trắng từ $25-32^{\circ} \mathrm{C}$. Trần Viết Mỹ (2009) cho rằng mặc dù tôm thẻ chân trắng có khả năng thích nghi rộng nhiệt trong khoảng $15-33^{\circ} \mathrm{C}$, nhưng ngưỡng nhiệt độ từ $27-$ $30^{\circ} \mathrm{C}$ được cho là tối ưu cho sự phát triển của đối tượng này.

Giá trị pH trong quá trình thí nghiệm cũng ít có sự dao động và duy trì trong khoảng $7,84-8,5$ ở các nghiệm thức. Các nghiên cứu trước đây cho rằng $\mathrm{pH}$ dao động từ $7,5-8,5$ nằm trong khoảng thích hợp cho nuôi tôm (Boyd, 2002; Whetstone et al., 2002) và trong ngưỡng 7,2-8,2 được xem là phù hợp cho sự phát triển của vi khuẩn nitrate hóa (Alleman, 1984). Như vậy, các thông số nhiệt độ và $\mathrm{pH}$ trong thời gian thí nghiệm đều nằm trong ngưỡng tối ưu cho tôm thẻ chân trắng sinh trưởng tôt.

\section{2. Độ mặn, oxy hòa tan (DO) và độ kiềm}

Các thông số chất lượng nước bao gồm độ mặn, hàm lượng oxy hòa tan và độ kiềm trong 63 ngày thí nghiệm được trình bày trong Bảng 1 .

Bảng 1. Chỉ tiêu độ mặn, hàm lượng oxy hòa tan và tổng kiềm trong thí nghiệm

\begin{tabular}{lrrrr}
\hline Thông số & Đối chứng & AOB TB7.2 & NOB TV4.2 & AOB TB7.2 và NOB TV4.2 \\
\hline Độ mặn (\%) & $14,7 \pm 0,5^{\mathrm{a}}$ & $14,7 \pm 0,5^{\mathrm{a}}$ & $14,7 \pm 0,5^{\mathrm{a}}$ & $14,7 \pm 0,5^{\mathrm{a}}$ \\
DO (mg/L) & $4,60 \pm 0,33^{\mathrm{a}}$ & $4,74 \pm 0,53^{\mathrm{a}}$ & $4,58 \pm 0,38^{\mathrm{a}}$ & $4,39 \pm 0,41^{\mathrm{a}}$ \\
Tổng kiềm $\left(\mathrm{mg} \mathrm{CaCO}_{3} / \mathrm{L}\right)$ & $104,1 \pm 12,1^{\mathrm{a}}$ & $103 \pm 12,8^{\mathrm{a}}$ & $101,6 \pm 15,8^{\mathrm{a}}$ & $100,2 \pm 13,4^{\mathrm{a}}$ \\
\hline
\end{tabular}

Các giá trị trung bình trên cùng một hàng có chũ cái giống nhau thì không khác biệt có ý nghĩa $(p<0,05)$ 
Bảng 1 cho thấy độ mặn trong các nghiệm thức luôn duy trì ở mức $14,7 \pm 0,5 \%$ và khác biệt không có ý nghĩa thống kê giữa các bể $(p>0,05)$. Hàm lượng oxy hòa tan giữa các nghiệm thức dao động trong khoảng 4,39-4,74 mg/L, đây được xem là khoảng thích hợp cho sự sinh trưởng của tôm. Theo Li et al. (2006), nồng độ oxy hòa tan lý tưởng cho sinh trưởng của tôm thẻ chân trắng trong ngưỡng $4,5-7 \mathrm{mg} / \mathrm{L}$ và quá trình nitrate hóa trong bể lọc sinh học được tối ưu khi nồng độ oxy hòa tan trong nước lớn hơn 4 mg/L (Stenstrom \& Poduska, 1980). Bên cạnh đó, độ kiềm ghi nhận giữa các bể dao động khoảng 81-126 $\mathrm{mg} \mathrm{CaCO}_{3} / \mathrm{L}$ trong suốt quá trình thí nghiệm. Về cuối giai đoạn thí nghiệm độ kiềm có xu hướng giảm mạnh, nguyên nhân do hoạt động tiêu thụ nguồn carbon vô cơ $\left(\mathrm{CO}_{3}{ }^{2-}\right)$ trong nước diễn ra bởi nhóm vi khuẩn nitrate hóa (Ebeling et al., 2006) và độ kiềm thiếu hụt do nguồn nước cấp vào. Hơn nữa, báo cáo trước đây của Piérri et al. (2015) cho rằng độ kiềm tổng cộng phù hợp cho tôm $L$. vannamei là $80 \mathrm{mg} \mathrm{CaCO}_{3} / \mathrm{L}$. Do đó, độ kiềm trong thí nghiệm hiện tại luôn được tối ưu bằng việc bổ sung Sodium bicarbonate $\left(\mathrm{NaHCO}_{3}\right.$, Ân Độ).

\subsection{Hàm lượng tổng đạm ammonia (TAN)}

Kết quả theo dõi cho thấy hàm lượng TAN (Hình 1) trong hệ thống tuần hoàn có xu hướng tăng nhanh trong 14 ngày nuôi, đạt giá trị cao nhất $(0,761 \pm 0,048$ $\mathrm{mg} / \mathrm{L}$ ) ở nghiệm thức đối chứng, trong khi nghiệm thức bổ sung đơn dòng $\mathrm{AOB}$ TB7.2, NOB TV4.2 và bổ sung kết hợp AOB TB7.2 với NOB TV4.2 đạt giá trị lần lượt $0,291 \pm 0,023 \mathrm{mg} / \mathrm{L} ; 0,634 \pm 0,049$ $\mathrm{mg} / \mathrm{L}$ và $0,415 \pm 0,009 \mathrm{mg} / \mathrm{L}$. Kết quả này cho thấy bổ sung vi khuẩn Nitrosomonas giúp giảm hàm lượng TAN thấp hơn và khác biệt có ý nghĩa thống kê $(p<0,05)$ so với hai nhóm nghiệm thức còn lại. Tuy nhiên, sau 14 ngày nuôi hàm lượng TAN ở nghiệm thức đối chứng và bổ sung đơn dòng $\mathrm{NOB}$ TV4.2 có xu hướng giảm đáng kể. Điều này cho thấy quần thể vi khuẩn oxi hóa ammonia xuất hiện và hoạt động mạnh sau 2 tuần thí nghiệm. Vào cuối giai đoạn thí nghiệm, từ ngày 28 trở đi, TAN ở các nghiệm thức biến động trong khoảng 0,098-0,259 $\mathrm{mg} / \mathrm{L}$ và không có khác biệt ở các nghiệm thức $(\mathrm{p}>0,05 ;$ Hình 1$)$. Nguyên nhân có thể là do sự phát triển của hệ vi khuẩn nội sinh trong giá thể sinh học đã chuyển hóa ammonia thành nitrite ở nghiệm thức đối chứng. Tương tự trong một báo cáo trước đây, quần thể vi khuẩn oxy hóa ammonia hình thành trong bể ương tôm thẻ chân trắng và chuyển hóa ammonia thành nitrite sau 5 tuần thí nghiệm (Correia et al., 2014) và chu kỳ xuất hiện nhóm quần thể vi khuẩn này phụ thuộc vào các yếu tố môi trường (Ferreira et al., 2015). Do đó, việc bổ sung vi khuẩn $\mathrm{AOB} \mathrm{TB} 7.2$ vào hệ thống nuôi đã thúc đẩy quá trình nitrate hóa diễn ra nhanh hơn so với hệ thống không bổ sung. Trong nuôi tôm biển, hàm lượng TAN khuyến cáo nhỏ hơn $2 \mathrm{mg} / \mathrm{L}$ (Chanratchakool, 2003) và mức này vẫn hơn gấp đôi mức cao nhất được ghi nhận trong thí nghiệm vào ngày 14 (Hình 1).

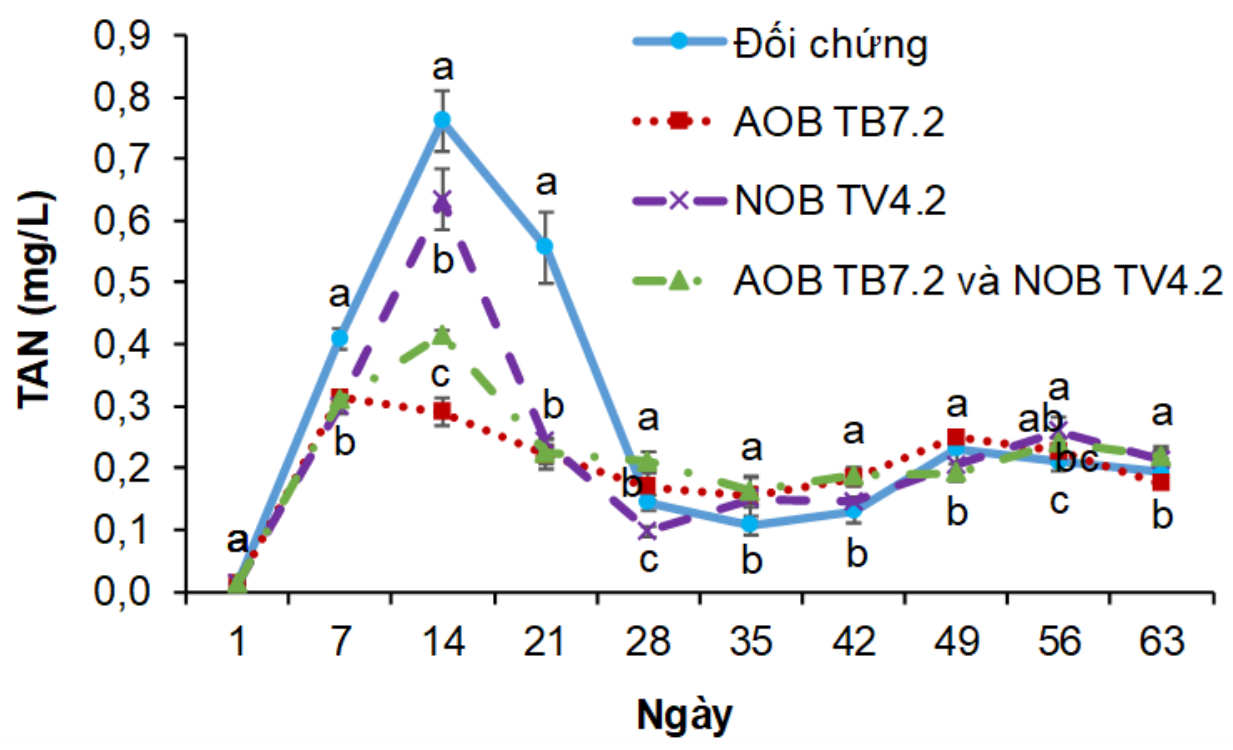

Hình 1. Biến động hàm lượng TAN trong thí nghiệm

Các ký tụ chũ cái trong cùng thời điểm thu mẫu khác nhau thi khác biệt có ý nghĩa thống kê $(p<0,05)$ 


\subsection{Hàm lượng nitrite $\left(\mathrm{N}-\mathrm{NO}_{2}{ }^{-}\right)$}

Dũ liệu ghi nhận được hàm lượng $\mathrm{N}^{-\mathrm{NO}_{2}}{ }^{-}$ở nghiệm thức đối chứng có chiều hướng tăng nhanh, cao hơn và khác biệt có ý nghĩa so với các nghiệm thức bổ sung vi khuẩn $(\mathrm{p}<0,05)$, đạt giá trị cao nhất $9,895 \pm 0,056 \mathrm{mg} / \mathrm{L}$ sau 35 ngày nuôi, sau đó giảm dần về cuối giai đoạn thí nghiệm và không khác biệt so với nhóm nghiệm thức còn lại ( $\mathrm{p}>0,05$; Hình 2$)$. Hàm lượng $\mathrm{N}^{-\mathrm{NO}_{2}}{ }^{-}$ở các nghiệm thức bổ sung vi khuẩn đơn dòng và kết hợp cũng tăng nhanh trong 28 ngày đầu thí nghiệm, trong đó nghiệm thức bổ sung đơn dòng AOB TB7.2 đạt giá trị trung bình $4,717 \pm 0,185 \mathrm{mg} / \mathrm{L}$ thấp hơn và khác biệt có ý nghĩa thống kê $(\mathrm{p}<0,05)$ với các nhóm nghiệm thức còn lại. Vào cuối giai đoạn thí nghiệm, hàm lượng N$\mathrm{NO}_{2}{ }^{-}$ở các nghiệm thức bổ sung vi khuẩn có chiều hướng giảm dần và giá trị thấp nhất ghi nhận ở nghiệm thức bổ sung đơn dòng $\mathrm{AOB}$ TB7.2 $(0,960 \pm 0,089 \mathrm{mg} / \mathrm{L})$. Theo Correia et al. (2014), nhóm vi khuẩn oxi hóa nitrite phát triển chậm trong

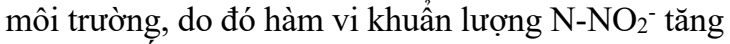
liên tục đến ngày nuôi thứ 35 và sau đó quá trình chuyển hóa nitrite thành nitrate diễn ra mạnh. Lin \& Chen (2003) khuyến cáo rằng nồng độ $\mathrm{N}-\mathrm{NO}_{2}{ }^{-}$nên thấp hơn $6.1 \mathrm{mg} / \mathrm{L}$ trong nuôi tôm thẻ chân trắng $L$. vannamei ở độ mặn $15 \%$. Kết quả ghi nhận cho thấy hàm lượng $\mathrm{N}-\mathrm{NO}_{2}{ }^{-}$ở các nghiệm thức bổ sung $\mathrm{AOB}$ $\mathrm{TB} 7.2$ và $\mathrm{NOB} T V 4.2$ nằm trong ngưỡng an toàn cho tôm phát triển.

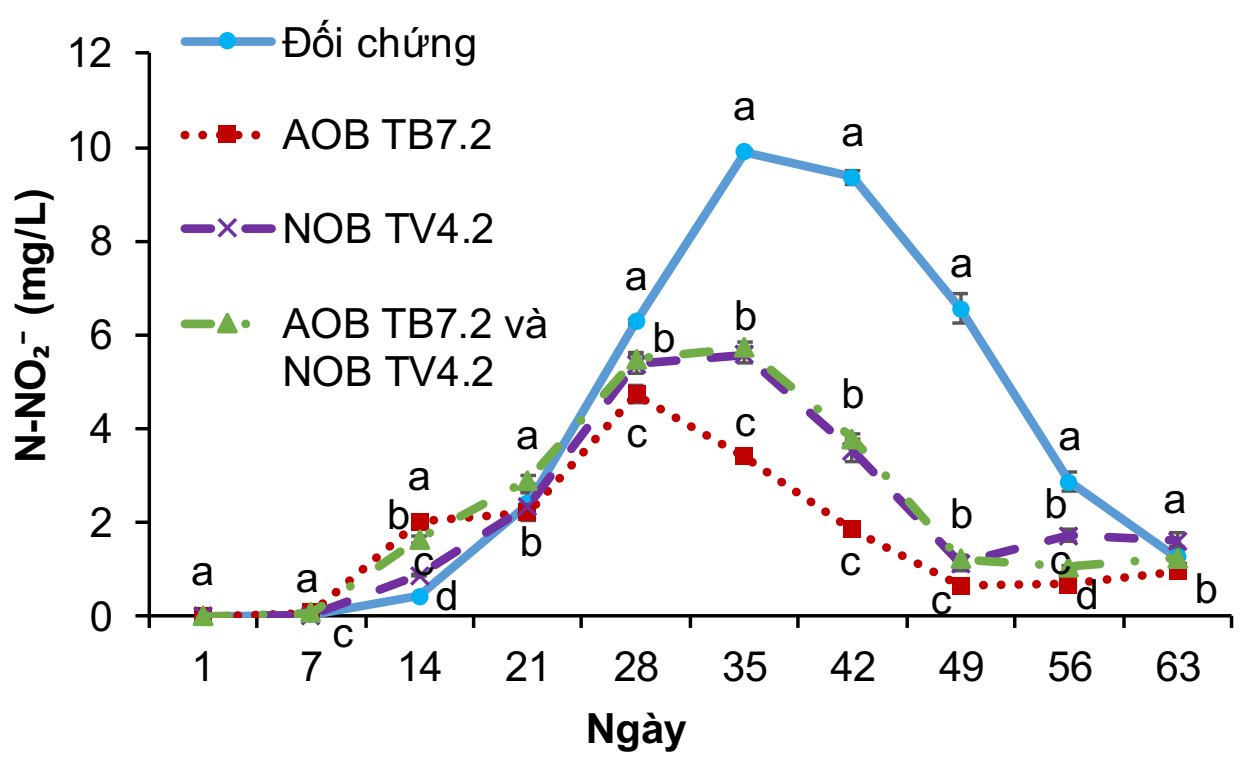

Hình 2. Biến động hàm lượng $\mathrm{N}-\mathrm{NO}_{2}^{-}$trong thí nghiệm

Các ký tụ chũ cái trong cùng thời điểm thu mẫu khác nhau thi khác biệt có ý nghĩa thống kê $(p<0,05)$

\subsection{Biến động hàm lượng nitrate $\left(\mathrm{N}-\mathrm{NO}_{3}^{-}\right)$}

Kết quả ghi nhận hàm lượng $\mathrm{N}-\mathrm{NO}_{3}{ }^{-}$của các nghiệm thức có xu hướng tăng theo thời gian nuôi (Hình 3). Trong 21 ngày đầu của thí nghiệm, hàm lượng $\mathrm{N}^{-\mathrm{NO}_{3}}{ }^{-}$ghi nhận ở các bể dao động trong khoảng 0,005-1,164 mg/L, trong đó nhóm nghiệm thức đối chứng và nghiệm thức bổ sung vi khuẩn NOB TV4.2 thấp hơn và khác biệt có ý nghĩa $(\mathrm{p}<0,05)$ so với hai nhóm nghiệm thức bổ sung vi khuẩn $\mathrm{AOB} T \mathrm{~TB} 7.2$ còn lại. Tuy nhiên, vào ngày nuôi thứ 21 kết quả ghi nhận không có sự khác biệt thống kê $(p>0,05)$ giữa các nghiệm thức trước khi tăng nhanh vào cuối giai đoạn thí nghiệm. Cụ thể là hàm lượng ${\mathrm{N}-\mathrm{NO}_{3}}^{-}$sau 63 ngày theo dõi ở nghiệm thức đối chứng đạt nồng độ $8,057 \pm 0,527 \mathrm{mg} / \mathrm{L}$, thấp hơn và khác biệt có ý nghĩa $(\mathrm{p}<0,05)$ so với nhóm nghiệm thức bổ sung vi khuẩn, trong khi đó hàm

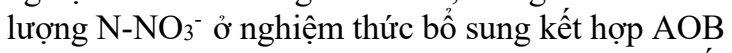
TB7.2 và NOB TV4.2 đạt giá trị cao nhất $(13,006 \pm 0,238 \mathrm{mg} / \mathrm{L})$. Kết quả cho thấy sự hiện diện của nhóm vi khuẩn $\mathrm{AOB}$ TB7.2 và NOB TV4.2 đã thúc đẩy quá trình nitrate hóa dẫn đến làm gia tăng hàm lượng $\mathrm{N}^{-\mathrm{NO}_{3}}{ }^{-}$vào cuối giai đoạn thí nghiệm. Trong nghiên cứu của Correia et al. (2014) cho thấy quá trình chuyển hóa nitrite thành nitrate trong bể tôm nuôi diễn ra sau 5 tuần thí nghiệm và hàm lượng $\mathrm{N}^{-\mathrm{NO}_{3}}{ }^{-}$đạt giá trị trung bình $95 \mathrm{mg} / \mathrm{L}$, tuy nhiên không ảnh hưởng đến sinh trưởng của tôm. Hàm lượng này cao hơn so với kết quả ghi nhận được trong nghiên cứu. 


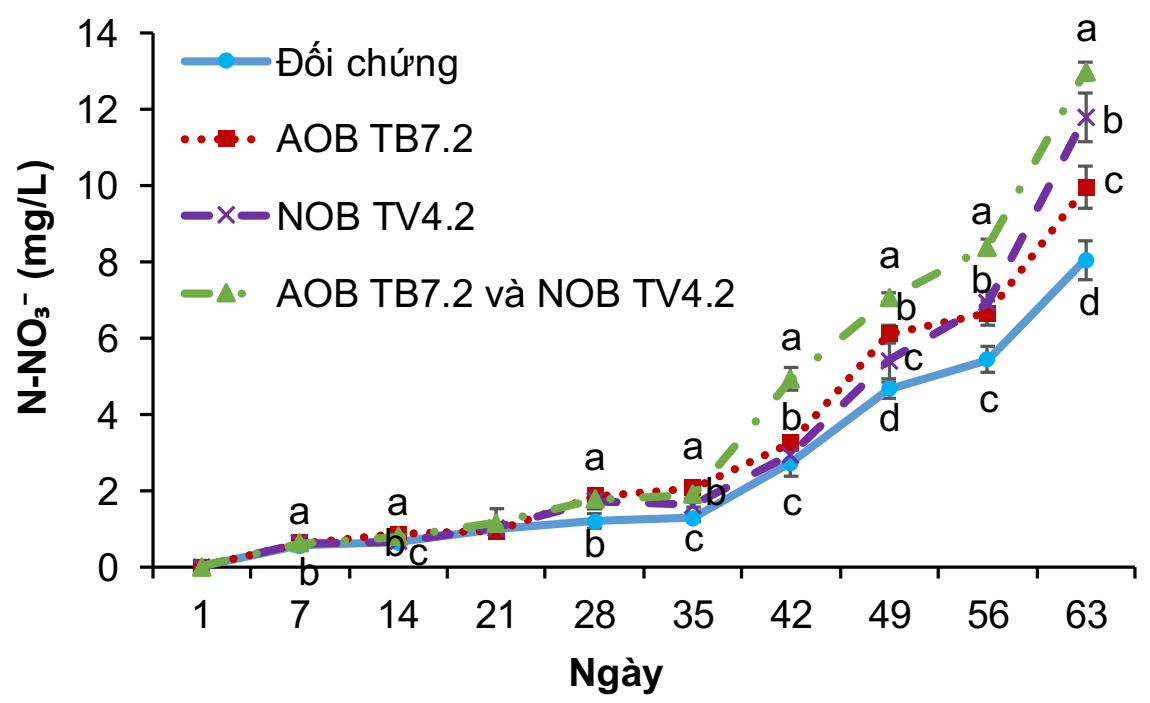

Hình 3. Biến động hàm lượng $\mathrm{N}-\mathrm{NO}_{3}{ }^{-}$trong thí nghiệm

Các ký tụ chũ cái trong cùng thời điểm thu mẫu khác nhau thi khác biệt có ý nghĩa thống kê $(p<0,05)$

Quá trình nitrate hóa trong hệ thống nuôi xảy ra do hoạt động của nhóm vi khuẩn oxy hóa ammonia (ammonia-oxidizing bacteria, $\mathrm{AOB}$ ) và nhóm vi khuẩn oxy hóa nitrite (nitrite-oxidizing bacteria, NOB). Nitrosomonas đại diện cho nhóm vi khuẩn $\mathrm{AOB}$ tham gia phản ứng chuyển hóa $\mathrm{NH}_{3} / \mathrm{NH}_{4}{ }^{+}$ thành $\mathrm{NO}_{2}^{-}$, sau đó sản phẩm $\mathrm{NO}_{2}^{-}$bị oxy hóa thành $\mathrm{NO}_{3}^{-}$khi có sự hiện diện của giống Nitrobacter (Hommes et al., 2003; Abeliovich, 2006). Trong thí nghiệm hiện tại, việc bổ sung các chủng vi khuẩn AOB TB7.2 và NOB TV4.2 đã gia tăng hiệu suất chuyển hóa đạm trong hệ thống, đặc biệt là ở các nghiệm thức bổ sung vi khuẩn AOB TB7.1. Vào giai đoạn đầu của thí nghiệm, nồng độ TAN tích tụ được coi là nguồn năng lượng chuyển hóa cho quá trình sinh tổng hợp của nhóm vi khuẩn $\mathrm{AOB}$. Nitrite
$\left(\mathrm{NO}_{2}{ }^{-}\right)$được biết là sản phẩm trung gian của quá trình nitrate hóa và cũng là yếu tố giới hạn lên sự phát triển của nhóm vi khuẩn NOB. Điều này thấy rõ khi vào giữa chu kỳ thí nghiệm, sự hiện diện của nồng độ $\mathrm{NO}_{2}^{-}$cao đã kích thích quá trình đồng hóa diễn ra ở vi khuẩn NOB nội sinh và vi khuẩn NOB TV4.2 tạo ra sản phẩm cuối là nitrate $\left(\mathrm{NO}_{3}{ }^{-}\right)$. Vì vậy ở các nghiệm thức được bổ sung dòng vi khuẩn AOB TB7.1 vào đầu giai đoạn thí nghiệm cho hiệu quả xử lý nước trong hệ thống tốt hơn.

\subsection{Tăng trưởng của tôm}

Các chỉ tiêu tăng trưởng của tôm bao gồm tỉ lệ sống, tốc độ tăng trưởng tuyệt đối (DWG) và tốc độ tăng trưởng tương đối (SGR) về khối lượng được xác định sau 63 ngày thí nghiệm (Bảng 2).

Bảng 2. Các chỉ tiêu tăng trưởng của tôm sau 63 ngày thí nghiệm

\begin{tabular}{lrrrr}
\hline \multirow{2}{*}{ Chỉ tiêu } & \multicolumn{3}{c}{ Nghiệm thức } \\
\cline { 2 - 5 } & \multicolumn{1}{c}{ Đối chứng } & AOB TB7.2 & NOB TV4.2 & AOB TB7.2 và NOB TV4.2 \\
\hline Khối lượng tôm bố trí $(\mathrm{g})$ & $0,47 \pm 0,1^{\mathrm{a}}$ & $0,47 \pm 0,1^{\mathrm{a}}$ & $0,47 \pm 0,1^{\mathrm{a}}$ & $0,47 \pm 0,1^{\mathrm{a}}$ \\
Khối lượng tôm thu $(\mathrm{g})$ & $5,59 \pm 0,04^{\mathrm{a}}$ & $5,69 \pm 0,27^{\mathrm{a}}$ & $5,68 \pm 0,13^{\mathrm{a}}$ & $5,81 \pm 0,09^{\mathrm{a}}$ \\
DWG (g/ngày) & $0,081 \pm 0,001^{\mathrm{a}}$ & $0,083 \pm 0,004^{\mathrm{a}}$ & $0,083 \pm 0,002^{\mathrm{a}}$ & $0,085 \pm 0,001^{\mathrm{a}}$ \\
SGR (\%/ngày) & $3,93 \pm 0,01^{\mathrm{a}}$ & $3,96 \pm 0,08^{\mathrm{a}}$ & $3,95 \pm 0,04^{\mathrm{a}}$ & $3,99 \pm 0,03^{\mathrm{a}}$ \\
Tỉ lệ sống (\%) & $81,67 \pm 0,04^{\mathrm{c}}$ & $94,33 \pm 0,03^{\mathrm{ab}}$ & $92,67 \pm 0,03^{\mathrm{b}}$ & $97 \pm 0,01^{\mathrm{a}}$ \\
\hline
\end{tabular}

Các giá trị trung bình trên cùng một hàng có chũ cái giống nhau thì không khác biệt có ý nghĩa $(p<0,05)$

Khối lượng tôm kết thúc thí nghiệm đạt giá trị trung bình $5,69 \pm 0,09 \mathrm{~g}$ và không có sự khác biệt giữa các nghiệm thức ( $>00,05)$. Kết quả ghi nhận tốc độ tăng trưởng theo ngày (DWG) và tốc độ tăng trưởng tương đối (SGR) ở nghiệm thức bổ sung kết hợp $\mathrm{AOB}$ TB7.2 và NOB TV4.2 đạt giá trị cao nhất lần lượt là $0,085 \pm 0,001 \mathrm{~g} /$ ngày và $3,99 \pm 0,03 \% /$ ngày, cũng không có sự sai khác về mặt 
thống kê trong nhóm so sánh $(\mathrm{p}>0,05)$. Điều này cho thấy việc bổ sung vi khuẩn nitrate hóa không ảnh hưởng trực tiếp đến sự tăng trưởng của tôm. Tuy nhiên, tỉ lệ sống của tôm ở nghiệm thức đối chứng đạt $81,67 \pm 0,04 \%$, thấp hơn và khác biệt có ý nghĩa $(\mathrm{p}<0,05)$ so với nhóm nghiệm thức bổ sung khuẩn, trong đó nghiệm thức bổ sung $\mathrm{AOB}$ TB7.2 và bố sung kết hợp với NOB TV4.2 đạt tỉ lệ sống cao nhất, lần lượt $94,33 \pm 0,03 \%$ và $97 \pm 0,01 \%$. Kết quả nghiên cứu hiện tại tương tự với một nghiên cứu trước, việc bổ sung giá thể chứa vi khuẩn nitrate hóa vào bể tôm nuôi đạt tỉ lệ sống $(72,44 \%)$ và tốc độ tăng trưởng tương đối $(12,86 \%)$ cao hơn và khác biệt có ý nghĩa $(\mathrm{p}<0,05)$ so với nhóm không bổ sung (Maya et al., 2013). Qua đó, việc bổ sung vi khuẩn nitrate hóa vào bể nuôi góp phần cải thiện tỉ lệ sống, giảm các chất gây độc $\left(\mathrm{NH}_{3}, \mathrm{NO}_{2}{ }^{-}\right)$trong hệ thống nuôi tôm thẻ chân trắng.

\section{KẾT LUẬN VÀ ĐỀ XUẤT}

\subsection{Kết luận}

Việc bổ sung vi khuẩn $\mathrm{AOB}$ TB7.2 và vi khuẩn NOB TV4.2 vào bể lọc sinh học trong hệ thống tuần hoàn làm giảm hàm lượng các khí độc ammonia và nitrite trong bể nuôi, tăng tỉ lệ sống và tái sử dụng được nguồn nước trong suốt chu kỳ nuôi, giảm thiểu tác động đến môi trường bên ngoài.

Bổ sung đơn dòng $\mathrm{AOB}$ TB7.2 và bổ sung kết hợp AOB TB7.2 với NOB TV4.2 thúc đẩy quá trình nitrate hóa diễn ra nhanh hơn so với bổ sung đơn dòng NOB TV4.2. Đặc biệt là quá trình nitrite hóa ở các nghiệm thức được bổ sung vi khuẩn $\mathrm{AOB}$ TB7.2 diễn ra trong 7 ngày, nhanh hơn so với nghiệm thức đối chứng là 14 ngày. Bên cạnh đó, quá trình nitrate hóa ở các nghiệm thức bổ sung khuẩn thể hiện rõ rệt sau 28 ngày thí nghiệm, trong khi ở nghiệm thức đối chứng là 35 ngày.

\section{2. Đề xuất}

Từ kết quả nghiên cứu trên, cần tiến hành các thí nghiệm đánh giá sự đa dạng của quần thể vi khuẩn trong hệ thống bể lọc sinh học bằng công nghệ giải trình tự gen thế hệ mới (Next Generation Sequencing - NGS) nhằm xác định sự phong phú và đa dạng của nhóm loài vi khuẩn nitrate hóa trong môi trường từ đó làm cơ sở khoa học cho nghiên cứu trên.

\section{LỜI CẢM TẠ}

Đề tài này được tài trợ bởi Dự án Nâng cấp Trường Đại học Cần Thơ VN14-P6 bằng nguồn vốn vay ODA từ Chính phủ Nhật Bản.

\section{TÀI LIỆU THAM KHẢO}

Abeliovich, A. (2006). The nitrite oxidizing bacteria. The prokaryotes, 5, 861-872.

Alleman, J.E. (1984). Elevated nitrite occurrence in biological wastewater treatment systems. Water Science and Technology, 17, 409-419.

APHA. (2017). Standard Methods for the Examination of Water and Wastewater. $23^{\text {rd }}$ Edition, American Public Health Association, American Water Works Association, Water Environment Federation, Denver, 1504 pp.

Boyd, C.E., Thunjai, T. \& Boonyaratpalin, M. (2002). Dissolved salts in water for inland low salinity shrimp culture. Global Aquaculture Advocate, (3), 40-45.

Carroll, P.M., Watanabe, W.O. \& Losordo, T.M. (2005). Pilot Production of Hatchery - Reared Summer Flounder Paralichthys dentatus in a Marine Recirculating Aquaculture System: The Effects of Ration Level on Growth, Feed Conversion, and Survival. Journal of the World Aquaculture Society, 36, 120-128.

Chanratchakool, P. (2003). Problem in Penaeus monodon culture in low salinity areas. Aquaculture Asia, 8(3), 53-56.

Correia, E.S., Wilkenfeld, J.S., Morris, T.C., Wei, L., Prangnell, D.I., \& Samocha, T.M. (2014). Intensive nursery production of the Pacific white shrimp Litopenaeus vannamei using two commercial feeds with high and low protein content in a biofloc-dominated system. Aquacultural Engineering, 59, 48-54.

Ebeling, J.M., Timmons, M.B., \& Bisogni, J.J. (2006). Engineering analysis of the stoichiometry of photoautotrophic, autotrophic, and heterotrophic removal of ammonia-nitrogen in aquaculture systems. Aquaculture, 257(1-4), 346-358.

Ferreira, G.S., Bolívar, N.C., Pereira, S.A., Guertler, C., Vieira, F.D.N., Mouriño, J.L.P. \& Seiffert, W.Q. (2015). Microbial biofloc as source of probiotic bacteria for the culture of Litopenaeusvannamei. Aquaculture, 448, 273-279.

Hommes, N. G., Sayavedra-Soto, L. A., \& Arp, D. J. (2003). Chemolithoorganotrophic growth of Nitrosomonas europaea on fructose. Journal of Bacteriology, 185(23), 6809-6814

Karthik, R., Pushpam, A.C., Chelvan, Y. \& Vanitha, M.C. (2015). Efficacy of probiotic and nitrifier bacterial consortium for the enhancement of Litopenaeus vannamei aquaculture. International Journal of Veterinary Science and Research, 1(1), 29-34.

Li, Y., Li, J., \& Wang, Q. (2006). The effects of dissolved oxygen concentration and stocking density on growth and non-specific immunity 
factors in Chinese shrimp, Fenneropenaeus chinensis. Aquaculture, 256, 608-616.

Lin, Y.C. \& Chen, J.C. (2003). Acute toxicity of nitrite on Litopenaeus vannamei (Boone) juveniles at different salinity levels. Aquaculture, 224(1-4), 193-201.

Luo, G., Gao, Q., Wang, C., Liu, W., Sun, D. L.L. \& Tan, H. (2014). Growth, digestive activity, welfare, and partial cost-effectiveness of genetically improved farmed tilapia (Oreochromis niloticus) cultured in a recirculating aquaculture system and an indoor biofloc system. Aquaculture, 422-423, 1-7.

Maya, E.N., Banerjee, S., Shariff, M. \& Yusoff, F. M. (2013). Screening, identification and immobilization of ammonia oxidizing bacteria consortium collected from mangrove areas and shrimp farms. Asian Journal of Animal and Veterinary Advances, 8: 73-81.

Mordenti, O., Casalini, A., Mandelli, M. \& Di Biase, A. (2014). A closed recirculating aquaculture system for artificial seed production of the European eel (Anguilla anguilla): Technology development for spontaneous spawning and eggs incubation. Aquacultural Engineering, 58, 88-94.

Palm, H.W., Knaus, U., Wasenitz, B., Bischoff, A.A. \& Strauch, S.M. (2018). Proportional up scaling of African catfish (Clarias gariepinus Burchell, 1822) commercial recirculating aquaculture systems disproportionally affects nutrient dynamics, Aquaculture. 491, 155-168.

Piérri, V., Valter-Severino, D., Goulart-de-Oliveira, K., Manoel-do-Espírito-Santo, C., NascimentoVieira, F. \& Quadros-Seiffert, W. (2015). Cultivation of marine shrimp in biofloc technology (BFT) system under different water alkalinities, Brazilian Journal of Biology. 75(3), 558-564.

Ray, A.J. \& Lotz, J.M. (2017). Shrimp (Litopenaeus vannamei) production and stable isotope dynamics in clear-water recirculating aquaculture systems versus biofloc systems, Aquaculture Research, 1-9.

Spieck, E. \& Bock, E. (2005). The Lithoautotrophic Nitrite-Oxidizing Bacteria. Bergey's Manual of Systematic Bacteriology, Volume 2 Part A Introductory Essays, 149-153.

Stenstrom, M.K., \& Poduska, R.A. (1980). The effect of dissolved oxygen concentration on nitrification, Water Research. 14(6), 643-649.

Stephen, J.R., McCaig, A.E., Smith, Z. Prosser, I. M \& Embley, M.T. (1996). Molecular diversity of soil and marine 16S Ribosomal RNA gene sequences related to $\beta$-subgroup Ammonia Oxidasing Bacteria. Appl. Environ. Microbiol, 62, 4147-4154.

Suantika, G., Turendro, O.R., \& Situmorang, M.L. (2017). Use of nitrifying bacteria for promoting giant freshwater prawn (Macrobrachium rosenbergii de Man) nursery hhase in indoor system. Journal of Fisheries \& Livestock Production, 5(2).

Thái Bá Hồ \& Ngô Trọng Lư, 2003. Kỹ thuật nuôi tôm thẻ chân trắng, Nhà xuất bản Nông nghiệp Hà Nội.

Whetstone, J.M., G.D. Treece, C.L.B \& Stokes, A.D. (2002). Opportunities and constraints in marine shrimp farming. Southern Regional Aquaculture Center (SRAC) Publication No. 2600 USA.

William, W., Amanda, M., Brian, V. \& Steven, S. (2009). Design, loading, and water quality in recirculating systems for Atlantic Salmon (Salmo salar) at the USDA ARS National Cold Water Marine Aquaculture Center (Franklin, Maine), 41(2), 60-70.

Vũ Thế Trụ. (2012). Cải tiến kĩ thuật nuôi tôm tại Việt Nam. Nhà xuất bản Nông nghiệp, Hà Nội. 